Disaster Management Framework for Afghanistan (DMFA) 


\section{Natural hazards}

- Earthquake

- Drought

- Flood

- Agricultural pests \& diseases

- Health issues/epidemic diseases

- Landslide \& soil erosions

- Avalanches 


\section{High vulnerability}

- Present situation of disorder/instability and humanitarian assistance and reconstruction;

- Current limitations on government capacity;

- Many communities have lost their assets and weakened their capacity to help themselves;

- There are particularly vulnerable groups of people, such as displaced people, critically poor, Kuchis. 


\section{Using assistance effectively}

- Many development partners giving humanitarian assistance.

- Many government departments also involved.

- Problems of poor coordination, lack of information sharing, duplication.

- A stronger government structure can better coordinate assistance and ensure that it builds towards national development goals. 


\section{Improving disaster management}

- Main goal: To strengthen the capacity of government and civil society in Afghanistan at national and sub-national levels, especially by:

$\checkmark$ Improving disaster mitigation, preparedness and response,

$\checkmark$ Implementing community-based projects that reduce peoples' vulnerability. 


\section{1: Develop a National Disaster Preparedness \& Response Plan}

- Develop national and sub-national plans and have them approved by Government;

- Promote them widely so that everyone knows their roles and responsibilities;

- Disaster management policy and institutional arrangements defined

- Establish emergency operations system and train Disaster Response Teams. 


\section{Information and Decision Flow}

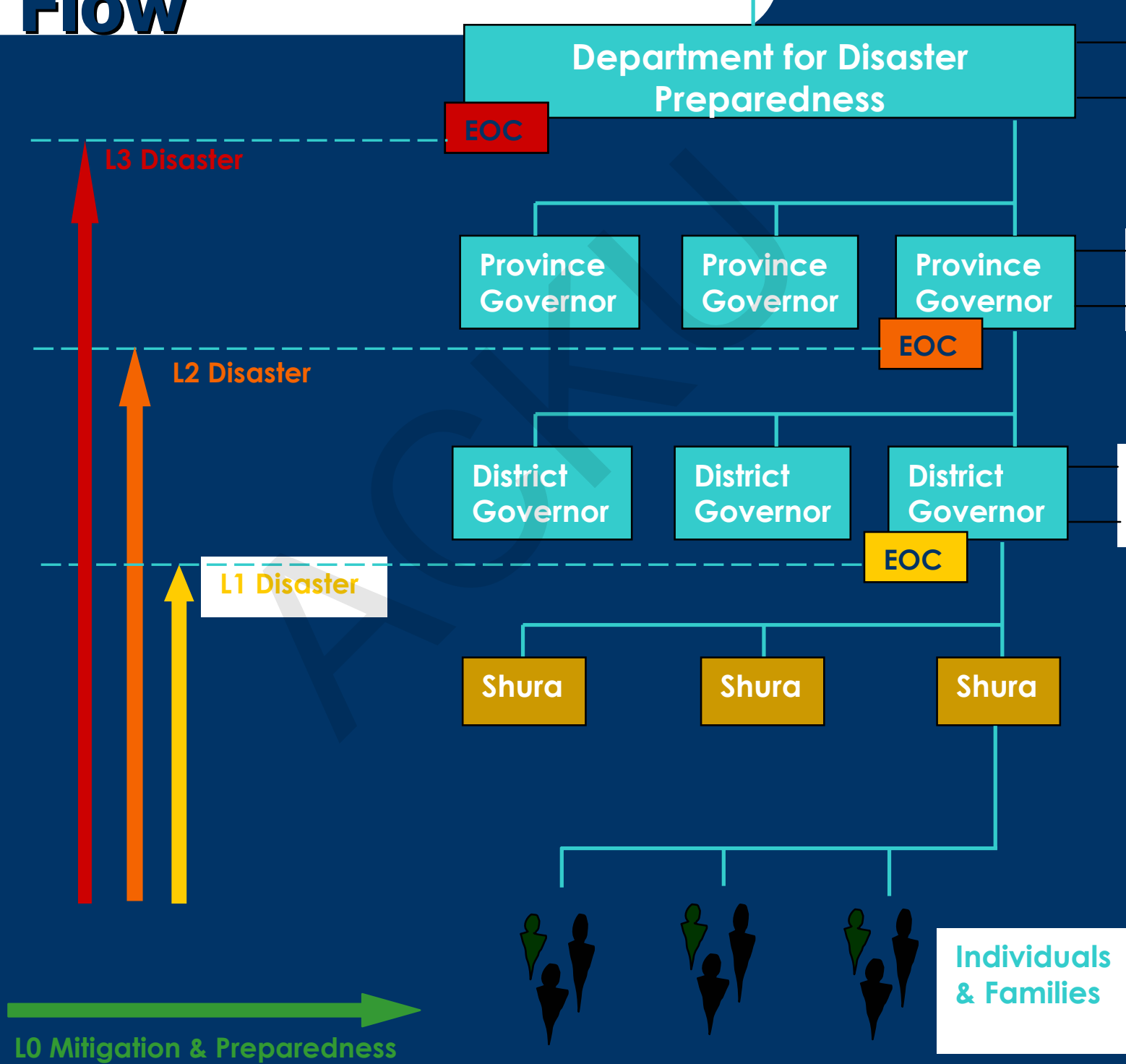

Line Ministries

INGOs/NGOs

Line Depts.

NGOs

Line Depts.

NGOs 
2. Provide disaster management training at national \& sub-national levels

- Assess training needs;

- Produce training materials;

- Design and conduct training programs;

- Establish a Disaster Management Training Unit within Government. 


\section{Implement projects to reduce the vulnerability of communities to natural disasters}

- Work with provincial governments and communities to assess and prioritize local needs and design Action Plans;

- Implement projects in collaborative ways between the community, local government and project team;

- Integrate project activities into overall development programs. 


\section{Conduct public education and awareness programs throughout Afghanistan}

- Select personnel from government ministries to form a Public Education and Awareness Task Force,

- Develop appropriate community disaster preparedness and response programs and develop materials,

- Launch campaigns. 


\section{Develop a Disaster Information Management System and national capacity to maintain it}

- Collate hazards and vulnerability data in GIS maps and database;

- Enable disaster managers and planners at all levels of government to use the data, e.g. by conducting training, applying it to reduce vulnerability;

- Compile information on successful communitylevel mitigation activities;

- Disseminate this information widely. 


\section{Reduce urban vulnerability through preparedness planning and mitigation activities}

- Develop preparedness \& response plans for urban areas to protect public health and safety;

- Assist municipalities to operationalize their plan;

- Conduct training for civil servants and community leaders;

- Develop building codes and standards and regulations to enforce them. 


\section{Develop early warning systems}

Produce an early warning system project plan for

(a) the national system;

(b) local communities with traditional systems;

Purchase and install necessary equipment and train personnel.

Implement community-based preparedness and action plans. 


\section{In key government sectors, establish mitigation measures to reduce disaster impacts}

- Reduce disaster vulnerability in the agriculture sector by implementing mitigation measures, e.g. by:

$\checkmark$ Developing and promoting land-use regulations to reduce soil erosion, flooding and drought;

$\checkmark$ Reducing locust/pests infestation through community action;

$\checkmark$ Improving irrigation and water management

- Improve emergency health and medical services, especially in disaster-prone areas, and

$\checkmark$ Develop preparedness and response plan;

$\checkmark$ Establish EHTF at national and sub-national 
9. Develop the legal base to implement National Disaster Management Policy and Plans

To produce disaster management Legislation which is passed by Cabinet and Parliament, promoted and enforced. 


\section{Afghanistan Emergency Trust Fund Projects}

1. Disaster Management Training Project

2. Community Disaster Awareness and Mitigation Project

3. Disaster Management Information System

4. Sub-National Disaster Management Plan

5. Disaster Relief Reserve Funds

6. Support to DDP 


\section{Thank you}

\section{Questions/Comments}

